OPEN ACCESS

Edited by:

Krisztian Kordas,

University of Oulu, Finland

Reviewed by:

Sápi András,

University of Szeged, Hungary

Janos Kiss,

University of Szeged, Hungary

*Correspondence:

Shashi Kant Shukla

shashi.kant.shukla@umu.se

Jyri-Pekka T. Mikkola

jyri-pekka.mikkola@umu.se

Specialty section

This article was submitted to Translational Materials Science,

a section of the journal

Frontiers in Materials

Received: 30 November 2018

Accepted: 22 February 2019

Published: 22 March 2019

Citation:

Shukla SK, Khokarale SG, Bui TQ and

Mikkola J-PT (2019) Ionic Liquids:

Potential Materials for Carbon Dioxide

Capture and Utilization.

Front. Mater. 6:42.

doi: 10.3389/fmats.2019.00042

\section{Ionic Liquids: Potential Materials for Carbon Dioxide Capture and Utilization}

\author{
Shashi Kant Shukla ${ }^{1 *}$, Santosh G. Khokarale ${ }^{1}$, Thai Q. Bui ${ }^{1}$ and Jyri-Pekka T. Mikkola ${ }^{1,2 *}$ \\ ${ }^{1}$ Technical Chemistry, Department of Chemistry, Chemical-Biological Centre, Umeå University, Umeå, Sweden, ${ }^{2}$ Industrial \\ Chemistry and Reaction Engineering, Department of Chemical Engineering, Johan Gadolin Process Chemistry Centre, Åbo \\ Akademi University, Åbo-Turku, Finland
}

The non-volatility, structure-tunability, and high $\mathrm{CO}_{2}$ uptake capacity render ionic liquids (ILs) the most exciting materials for the carbon dioxide $\left(\mathrm{CO}_{2}\right)$ capture and fixation to value-added chemicals. The aim of this mini-review is to give a brief idea about the development of the potential ILs for $\mathrm{CO}_{2}$ capture, the mechanism involved in the $\mathrm{CO}_{2}$ binding and the application of ILs in the conversion of $\mathrm{CO}_{2}$ to useful chemicals. The mechanisms and nature of interactions in between $\mathrm{IL}-\mathrm{CO}_{2}$ have been discussed in terms of the nature of cation, anion, presence of functional group, and the extent of interaction between the components of ILS. The fixation of $\mathrm{CO}_{2}$ to linear and cyclic carbonates and electroreduction of $\mathrm{CO}_{2}$ to carbon-rich fuels in ILs has been accounted in detail. At the end, future challenges in terms of commercializing the ILs for $\mathrm{CO}_{2}$ capture and utilization technology are discussed.

\begin{abstract}
Keywords: ionic liquid (IL), $\mathrm{CO}_{2}$ capture, mechanism of $\mathrm{CO}_{2}$-IL interaction, electrochemical reduction, dimethyl carbonate and faradaic efficiency
\end{abstract}

\section{INTRODUCTION}

Carbon dioxide $\left(\mathrm{CO}_{2}\right)$ emissions to the atmosphere give rise to negative environmental impacts as the release of it causes greenhouse effect leading to global warming (Ben-Mansour et al., 2016; SanzPerez et al., 2016). Apart from the anthropogenic activities, which account for the major release of the $\mathrm{CO}_{2}$ into the environment, the energy gas resources, like natural or shale gas, syngas, and biogas, also contain a significant fraction of $\mathrm{CO}_{2}$ lowering the heating value of gases, causing corrosion of equipment and demanding high energy cost during conversion and transportation (Huang et al., 2014; George et al., 2016). Therefore, developing technologies that can capture $\mathrm{CO}_{2}$ have been of prime importance. One such technology is carbon dioxide capture and sequestration (CCS) where aqueous amine [typically monoethanolamine (MEA) and methyldiethylamine (MDEA)] are used as scavengers in $\mathrm{CO}_{2}$ capture (Thitakamol et al., 2007). These solvents have several disadvantages such as high volatility, high cost, substantial energy consumption and corrosiveness and, therefore, designing new solvents is of prime importance (Shao and Stangeland, 2009). Ionic liquids (ILs) possess unique characteristics over the volatile organic compounds (VOCs) and have been explored in various chemical and biological applications (Steinruck and Wasserscheid, 2015). In the past decade, they were extensively studied as scrubbers of greenhouse gases (Zeng et al., 2017). The initial interests in these solvents emerged because of their negligible vapor pressure, high thermal stability, wide liquidus range, relative non-flammability, designability, and recyclability. The designability gives an extra edge to ILs over conventional scrubbers like MEA and MDEA and large number of potential ILs have been designed to achieve optimum $\mathrm{CO}_{2}$ solubility. Of these, 
the representative class consists of imidazolium, pyridinium, pyrrolidinium, guanidinium and amine cations, and organic/inorganic (carboxylate, azolate, phenoxide, prolinate, thionate, halide, tetrafluoroborate, hexafluorophosphate, anion, etc (Zhang Y. Q. et al., 2009; Goodrich et al., 2011; Niedermaier et al., 2014). Contrary to the cation, the basicity of the anion was noted to influence more the $\mathrm{CO}_{2}$ uptake in ILs. Process simulations showed that use of ILs in place of well-known MDEA can bring down the total electrical and thermal energy by 42.8 and $66.04 \%$, respectively (Liu et al., 2016). The regeneration energy demand also decreased by $15 \%$ when IL (1-butylpyridinium tetrafluoroborate) was used in place of MEA (Mumford et al., 2015).

The major drawback of ILs as a scrubbing agent arises from their high viscosity which further increases upon $\mathrm{CO}_{2}$ capture. For example, the viscosity of 3-aminopropyl tributylphosphoniumamino acid $\left(\left[\mathrm{aP}_{4443}\right][\mathrm{AA}]\right)$ and

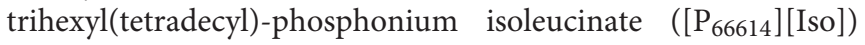
increased 3- and 200-fold, respectively, upon $\mathrm{CO}_{2}$ capture (Liu et al., 2009; Gurkan et al., 2010a). However, the high viscosity of ILs can be lowered by incorporating ether functionality, imidazolate anion, addition of molecular solvents, and incorporating them on polymer membrane. The viscosity of trihexyl-(tetradecyl)phosphonium imidazolate $\left(\left[\mathrm{P}_{66614}\right][\mathrm{Im}]\right)$ was lowered upon $\mathrm{CO}_{2}$ capture from 810.4 to $648.7 \mathrm{mPa}$.s because of the combined effect of physisorption and chemisorption (Wang et al., 2011). Similarly, the addition of ether functionality in ILs lowered the viscosity by $43 \%$ compared to non-functionalized ILs (Zeng et al., 2015). The addition of amine-based solvent in ILs also decreases viscosity exponentially without affecting the $\mathrm{CO}_{2}$ uptake (Zhao et al., 2011).

The Carbon Capture Storage and Utilization (CCSU), which comprises all the efforts taken to reduce the $\mathrm{CO}_{2}$ release in environment and its conversion to value-added products, has been worldwide accepted as the strategy to reduce the negative environmental effects of $\mathrm{CO}_{2}$. Due to their dual nature, both as catalyst and solvent, ILs have been utilized in the conversion of $\mathrm{CO}_{2}$ to useful organic moieties like, linear and cyclic carbonates, carbonmonooxide, methanol, formic acid/formates etc (Alvarez-Guerra et al., 2015). The electrochemical reduction of $\mathrm{CO}_{2}$ is interesting as it operates at low temperatures and pressures. The electro-reduction of $\mathrm{CO}_{2}$ requires an aqueous electrolyte medium which can absorb $\mathrm{CO}_{2}$ and decrease the over-potential required to give rise to the $\mathrm{CO}_{2}^{-}$. radical anion in the presence of a metal cathode (Ag, $\mathrm{Au}, \mathrm{Pt}$, etc.) (Oh and $\mathrm{Hu}, 2013$ ). Similarly, $\mathrm{CO}_{2}$ can yield linear and cyclic carbonates at elevated temperatures and pressures. Thus, ILs serve the purpose because of the high $\mathrm{CO}_{2}$ uptake efficiency (Xu et al., 2015).

\section{Ionic Liquids in Carbon Dioxide Capture}

The pioneering work of Blanchard et al. showed for the first time that IL (1-butyl-3-methylimidazolium hexafluorophosphate, $\left.[\mathrm{BmIm}]\left[\mathrm{PF}_{6}\right]\right)$ can be employed in $\mathrm{CO}_{2}$ capture. Since then, plethora of research unraveling the mode and mechanism of $\mathrm{CO}_{2}$ capture in conventional and functionalized ILs have been reported. In conventional ILs, the cation plays a minor role and the basicity of the anion is observed to affect the $\mathrm{CO}_{2}$ adsorption. Higher $\mathrm{CO}_{2}$ uptake was attained in task-specific ILs despite their high viscosity. In this regard, superbase-derived ILs were tested for the optimum $\mathrm{CO}_{2}$ uptake (Rebecca et al., 2015). Bates et al. (2002) reported semimolar $\mathrm{CO}_{2}$ absorption in amino-functionalized ILs under ambient conditions. Gurkan et al. (2010b) succeeded in the equimolar absorption with amino acid-based ILs containing prolinate and methioninate anions with phosphonium cation. Later, Wang et al. (2011) achieved equimolar absorption in ILs comprised of pyrazolate, imidazolate, triazolate, tetrazolate, indolate, and oxalate anion and phosphonium cation thus obtaining a linear correlation between the $\mathrm{CO}_{2}$ capacity and basicity $\left(\mathrm{p} K_{\mathrm{a}}\right)$ of ILs in DMSO. Multimolar $\mathrm{CO}_{2}$ absorption $\left(1.69 \mathrm{~mol}^{\mathrm{mol}}{ }^{-1}\right.$ ) was observed during the activation of carboxylic group in aminofunctionalized ILs (Chen et al., 2016). The carboxylate group in the vicinity of $\mathrm{NH}$ - moiety stabilizes the $\mathrm{CO}_{2}$ at the carbamic acid stage, thereby promoting the multimolar absorption. Similarly, a combined experimental and theoretical study on hydroxyl IL with phenolate anion showed 1.5 equivalent $\mathrm{CO}_{2}$ uptake as both hydroxyl and phenoxide groups participated in the absorption (Vafaeezadeh et al., 2015).

\section{MECHANISMS OF CARBON DIOXIDE CAPTURE IN ILS}

Besides the $\mathrm{CO}_{2}$ uptake efficiency and selectivity, the mode of IL$\mathrm{CO}_{2}$ interaction also reveals important information in terms of selection of components and functionality for designing potential ILs. In $\left[\mathrm{BF}_{4}\right]$ - and $\left[\mathrm{PF}_{6}\right]$-based ILs, an acid-base interaction was observed operating between the acetate anion and $\mathrm{CO}_{2}$ (ATR-IR spectroscopy, Raman spectroscopy and DFT calculations) (Kazarian et al., 2000; Cabaco et al., 2011). Though acid-base interaction shed light on the interaction mechanism, it is not the sole reason for $\mathrm{CO}_{2}$ uptake as the uptake efficiency doesn't follow the basicity order (Lei et al., 2014). The shortcomings of acid-base theory were later explained by the amount of free-volume in the IL system (Aki et al., 2004). The longer alkyl chain on cation and high anion fluorination increase the extent of free-volume and hence increase $\mathrm{CO}_{2}$ solubility (Muldoon et al., 2007; Almantariotis et al., 2010). For example, 1-hexyl3-methylimidazoliumtris(pentafluoroethyl) trifluorophosphate ([HmIm][FEP]) showed $70 \%$ higher $\mathrm{CO}_{2}$ solubility than $[\mathrm{HmIm}]\left[\mathrm{PF}_{6}\right]$ because of the presence of six $\mathrm{CF}_{2} / \mathrm{CF}_{3}$ in $[\mathrm{FEP}]$ than $\left[\mathrm{PF}_{6}\right]$ and hence leads to larger free-volume (obtained by Monte Carlo and MD simulations) (Zhang X. C. et al., 2009). Apart from these, weak interactions such as hydrogen and halogen bonding were shown to affect the $\mathrm{CO}_{2}$ uptake (Palomar et al., 2011; Zhu et al., 2011). The $\mathrm{CO}_{2}$ capture mechanism in $[\mathrm{HmIm}]\left[\mathrm{PF}_{6}\right]$ and $[\mathrm{FEP}]$ showed the importance of electrostatic interaction in the $\mathrm{CO}_{2}$ uptake in smaller and symmetrical $\left[\mathrm{PF}_{6}\right]$ anion whereas the van der Waals interaction has a key role in large and asymmetrical [FEP] anion (Zhang X. C. et al., 2009). In case of gas-[BmIm] cation complex, $\mathrm{CO}_{2}$ interacts with cation by the formation of hydrogen bond on the $\mathrm{C} 2$ carbon (Zhao et al., 2015). 


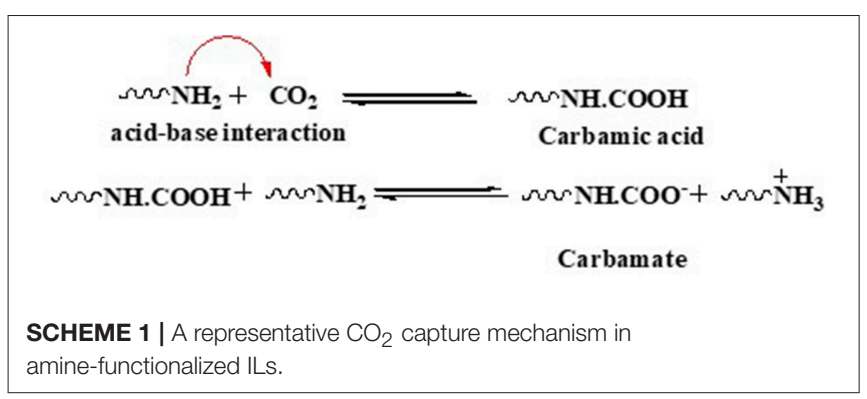

The amine- $\mathrm{CO}_{2}$ interaction in ILs follows two mechanisms, namely semimolar and equimolar, depending on the presence of amine moiety on cation or anion in ILs (Bates et al., 2002). It is noted that ILs cation tethered with amine moiety follows semimolar mechanism while an equimolar mechanism operates if the amine is a part of the anion (Cao et al., 2016). A molar uptake plot clearly reveals the type of operative mechanism in a medium. In semimolar mechanism, $\mathrm{CO}_{2}$ first reacts with amine moiety to form carbamic acid which further reacts with another molecule of amine to yield ammonium carbamate as the final product (Scheme 1). Thus, for one mole of $\mathrm{CO}_{2}$, two moles of amine are required.

In equimolar mechanism, one mole of amine captures one mole of $\mathrm{CO}_{2}$ and stabilizes the product as carbamic acid (Kasahara et al., 2016). Various studies have claimed multimolar absorption in ILs because of the presence of stabilizing group in the vicinity of $\mathrm{NH}_{2}$ - moiety of the amine (Luo et al., 2014).

Though amine-functionalized ILs improves $\mathrm{CO}_{2}$ solubility in ILs, high viscosity and regeneration of ILs remain as challenges. To address these problems Wang et al. (2010) proposed nonamine functionalized superbase-derived protic ILs for equimolar $\mathrm{CO}_{2}$ capture. Later, phenolic ILs were prepared from the phosphonium hydroxide and substituted phenols whereupon the effect of position and nature of substituents on the anion were correlated with the physicochemical properties and $\mathrm{CO}_{2}$ uptake efficiency (Wang et al., 2012). Thus, cation-anion interaction strength affects the $\mathrm{CO}_{2}$ uptake in phenolic ILs (Lee et al., 2016).

\section{APPLICATIONS OF IONIC LIQUIDS IN CONVERSION OF CARBON DIOXIDE TO VALUE-ADDED PRODUCTS}

IL-mediated conversion of $\mathrm{CO}_{2}$ to value added products has been achieved through chemical, thermochemical, photochemical, biochemical, and electrochemical reduction methods (Barton et al., 2008; Chueh et al., 2010; Rosen et al., 2011; Chen et al., 2012; Costentin et al., 2012). Out of these methods, chemical and electrochemical reduction of $\mathrm{CO}_{2}$ are the most attractive methods. In the chemical conversion method, epoxides and methanol were employed to convert $\mathrm{CO}_{2}$ to cyclic and linear carbonates, respectively, via cycloaddition reactions. The electrochemical reduction of $\mathrm{CO}_{2}$ is highly popular because of its higher conversion efficiency, product selectivity and its potential to store electrical energy from renewable energy sources like the sun (Spinner et al., 2012).

\section{Conversion of $\mathrm{CO}_{2}$ to Organic Carbonates}

Organic carbonates have many industrial applications as green aprotic polar solvents, electrolytes for lithium-ion batteries as well as intermediates upon production of pharmaceuticals and polymers (Chaugule et al., 2017). This mini-review highlights recent findings in catalysis converting $\mathrm{CO}_{2}$ to organic carbonates based on ILs under mild conditions (low temperature and pressure).

\section{Five-Membered Ring Cyclic Carbonate}

Traditional ILs-based catalysis for cyclic carbonates synthesis from $\mathrm{CO}_{2}$ was reported first time in 2001 (Peng and Deng, 2001). In this study, a series of RTILs based on cations $\left(\mathrm{BmIm}^{+}\right.$, $\left.\mathrm{BPy}^{+}\right)$and anions $\left(\mathrm{Cl}^{-}, \mathrm{BF}_{4}^{-}, \mathrm{PF}_{6}^{-}\right)$acted as recyclable catalysts to produce propylene carbonate from propylene oxide and $\mathrm{CO}_{2}$ in the absence of a solvent. Among them, $\left[\mathrm{Bmim}^{-}\right]\left[\mathrm{BF}_{4}\right]$ showed the highest catalyst activity with $100 \%$ yield under optimal conditions $\left(110^{\circ} \mathrm{C}, 6 \mathrm{~h}, 2.5 \mathrm{MPa}\right.$ of $\mathrm{CO}_{2}, 2.5 \mathrm{mmol}$ of [BmIm] $\left[\mathrm{BF}_{4}\right]$ per $100 \mathrm{mmol}$ of epoxide). Until now, numerous other ILs including new generations such as task-specific ILs were investigated for improving the production of cyclic carbonates under different experimental conditions (Chaugule et al., 2017).

Recently, a dual-IL system as a recyclable, efficient catalyst for cyclic carbonate synthesis under mild, solvent-free conditions was developed ( $\mathrm{Hu}$ et al., 2018). In this study, $\left[\mathrm{TMGH}^{+}\right]\left[-\mathrm{O}_{2} \mathrm{MMIm}^{+}\right] \mathrm{Br}^{-}$showed the best catalytic performance with $84 \%$ yield under optimal conditions $\left(30^{\circ} \mathrm{C}, 12 \mathrm{~h}, 0.1 \mathrm{MPa}\right.$ of $\mathrm{CO}_{2}, 0.5 \mathrm{mmol}$ of IL per $2 \mathrm{mmol}$ of epichlorohydrin). The mechanism was also suggested, wherein a synergistic catalytic effect among carboxylate anion, bromide anion and the $\mathrm{N}-\mathrm{H}$ bond of the iminium ion results in the cycloaddition of $\mathrm{CO}_{2}$ and epoxide.

Moreover, to render the catalyst separation and reusability issues easier and practical in industry, the immobilization of ILs-based catalysts on recyclable solid supports has been widely studied (Chaugule et al., 2017). Several ILs such as [BmIm] [X] (where $\mathrm{X}=\mathrm{Cl}, \mathrm{Br}, \mathrm{I}$ ) and $[\mathrm{EpIm}][\mathrm{X}]$ were immobilized on commercial $\mathrm{SiO}_{2}$ (pore size $6 \mathrm{~nm}, 35-70 \mu \mathrm{m}$ ) to yield efficient catalysts to produce cyclic carbonates under mild conditions (Martínez-Ferraté et al., 2018). Silica-supported [EpIm]Br was the best system reaching $99 \%$ conversion in just 30 min under optimal conditions $\left(80^{\circ} \mathrm{C}, 5\right.$ bar of $\mathrm{CO}_{2}, 1.67 \mathrm{mmol}$ of IL per $3.34 \mathrm{mmol}$ of propylene oxide). This catalyst system was still active ( $79 \%$ conversion) when using a model gas mixture from an industrial exhaust $\left(15 \% \mathrm{CO}_{2}\right)$ instead of synthetic $\mathrm{CO}_{2}$.

\section{Dimethyl Carbonate}

Recently, in the presence of different organic and inorganic bases, several imidazolium hydrogen carbonate ILs $\left([\mathrm{CnCmIm}]\left[\mathrm{HCO}_{3}\right]\right.$ ) were used (recyclable catalyst and dehydrant) upon straightforward synthesis of dimethyl carbonate from $\mathrm{CH}_{3} \mathrm{OH}$ and $\mathrm{CO}_{2}$, at room temperature and $1 \mathrm{MPa}$ of $\mathrm{CO}_{2}$ (Zhao et al., 2017). Under optimal conditions, a combination between $[\mathrm{BmIm}]\left[\mathrm{HCO}_{3}\right]$ and $\mathrm{Cs}_{2} \mathrm{CO}_{3}$ in the presence of $\mathrm{CH}_{2} \mathrm{Br}_{2}$ solvent showed the highest conversion of $\mathrm{CH}_{3} \mathrm{OH}(74 \%)$ and was easily reused. 


\section{Electrochemical Fixation of $\mathrm{CO}_{2}$ in ILs}

$\mathrm{CO}_{2}$ is an abundantly available renewable $\mathrm{C} 1$ feedstock from various emission sources such as coal fired power plants, biorefineries, crude oil processing industries etc (Friedlingstein et al., 2011). In the view of the negative impact of $\mathrm{CO}_{2}$ on environment, its conversion to fuels and fine chemicals could be a way to eliminate the harmful effects of this greenhouse gas (Ansari and Park, 2012). The electrochemical and photochemical approaches were undertaken to convert $\mathrm{CO}_{2}$ into useful chemicals such as methanol, carbon monoxide, ethylene, formic acid/formate, higher alcohols, alkanes etc. as well as important building blocks to synthesize various platform chemicals as well as polymers (Xiaoding and Moulijn, 1996). The electrochemical process involves cathodic reduction of $\mathrm{CO}_{2}$ and anodic oxidation of solvent.

The centrosymmetric structure makes $\mathrm{CO}_{2}$ electrically neutral though it has a bond dipole. Scheme 2 shows steps through which $\mathrm{CO}_{2}$ is reduced to various useful products, at different standard potentials $\left(\mathrm{E}^{0}\right)$. The hydrogen formed in these reactions is an undesired major byproduct and should be avoided (Feng et al., 2018a). To eliminate $\mathrm{H}_{2}$ from the process, a non-aqueous medium is required and room temperature ionic liquids (RTIL) are ideal in this regard.

\section{Electrochemical Conversion of $\mathrm{CO}_{2}$ to $\mathrm{CO}$}

RTILs as a dual medium were extensively explored in the electrochemical conversion of $\mathrm{CO}_{2}$ to $\mathrm{CO}$ during the last decade. Rosen et al. (2011) studied electrochemical reduction of $\mathrm{CO}_{2}$ to $\mathrm{CO}$ in $18 \%$ aqueous 1-ethyl-3-methylimidazolium tetrafluoroborate $\left([\mathrm{Emim}]\left[\mathrm{BF}_{4}\right]\right)$ and observed high Faradaic efficiency $(96 \%$ for $7 \mathrm{~h})$ with extremely low potential. The RTIL cation was noted to reduce the $\mathrm{H}_{2}$ generation thereby assisting in the reduction of $\mathrm{CO}_{2}$ to $\mathrm{CO}$. Later, several ILs comprised of imidazolium, pyrrolidinium, ammonium, phosphonium cation and (bis(trifluoromethylsulfonyl)imide $\left(\left[\mathrm{NTf}_{2}\right]\right)$, tris(pentafluoroethyl)trifluorophosphate ([FAP]), and tetrafluoroborate $\left[\mathrm{BF}_{4}\right]$ ) anion and role of substituents on the cationic core was investigated in the reduction of $\mathrm{CO}_{2}$ to $\mathrm{CO}$ (Alvarez-Guerra et al., 2015; Lim and Kim, 2017). In all these

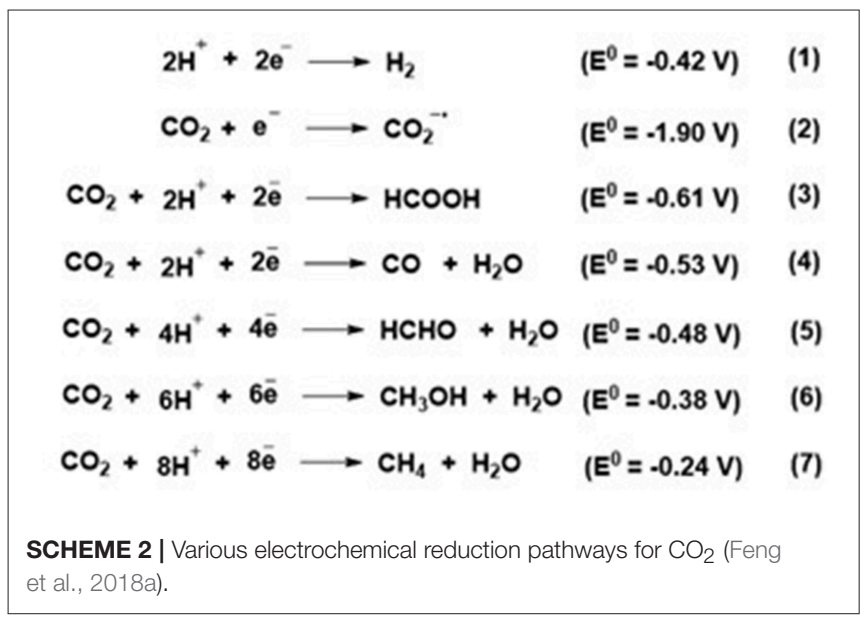

studies $\mathrm{Au}, \mathrm{Ag}, \mathrm{Pt}$, and glassy carbon-based cathodes were used as electro-catalysts (Alvarez-Guerra et al., 2015). During the reduction, the IL cation coordinates with $\mathrm{CO}_{2}$ molecule and forms $\mathrm{CO}_{2} \cdot{ }^{-}$radicals under negative electrode potential which subsequently form CO (Sun et al., 2014; Feng et al., 2018b).

In other words, as shown in Figure 1, the electrochemical reduction of $\mathrm{CO}_{2}$ to $\mathrm{CO}$ follow alternative path where the conversion proceeds with low overpotential compared with the case when there is an IL involved in the process. In reality, IL activates $\mathrm{CO}_{2}$ molecule via formation of "cation$\mathrm{CO}_{2}$ " intermediate through which the formation energy of $\mathrm{CO}_{2}^{-}$. radical anion decreases.

Alternatively, as shown in Figures 2, 3, Sun et al. (2014) proposed a mechanism for the electrochemical reduction of $\mathrm{CO}_{2}$ to $\mathrm{CO}$ in the absence and presence of an IL at the Pd electrode in acetonitrile. In this case, based on the experimental evidence, the author proposed that the precense of an IL switches the course of electrochemical reduction of $\mathrm{CO}_{2}$ where the IL favors the $\mathrm{CO}$ formation pathway instead of the undesirable oxalate anion formation.

As shown in Figure 2, the in-situ formed $\mathrm{CO}_{2}^{-}$radical anion formed over the Pd electrode further dimerizes to an oxalate anion in the absence of an IL. On the other hand, as shown in Figure 3, the IL stabilizes $\mathrm{CO}_{2}^{-}$and prevents its dimerization whereupon this stabilized $\mathrm{CO}_{2}^{-}$. further converts to $\mathrm{CO}$ molecule.

Additionally, it was also observed that along with $\mathrm{CO}$ formation, the imidazolium carboxylate formation pathway also exists (Figure 4). An earlier theoretical as well as experimental studies study performed by Zhao et al. (2016) claims that the formation of this carboxylate species deactivates the active sites on the imidazolium cation. However, these active imidazolium sites can be recovered by an addition of a proton source such as water.

Further, based on the density functional theory (DFT) as well as Raman and NMR spectroscopic techniques, Wang et al. (2015) also represented another alternative mechanism

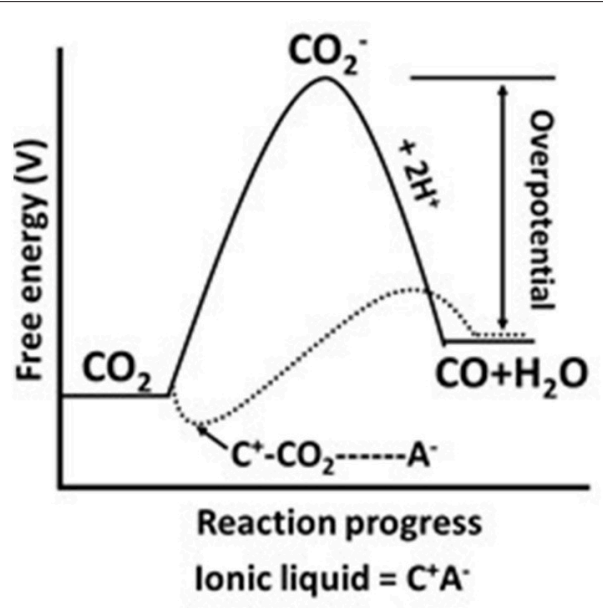

FIGURE 1 | Schematic representation for free energy change for electrochemical conversion of $\mathrm{CO}_{2}$ to $\mathrm{CO}$ in water (solid line) or ionic liquid (dotted line). Adopted from Li et al. (2013). 


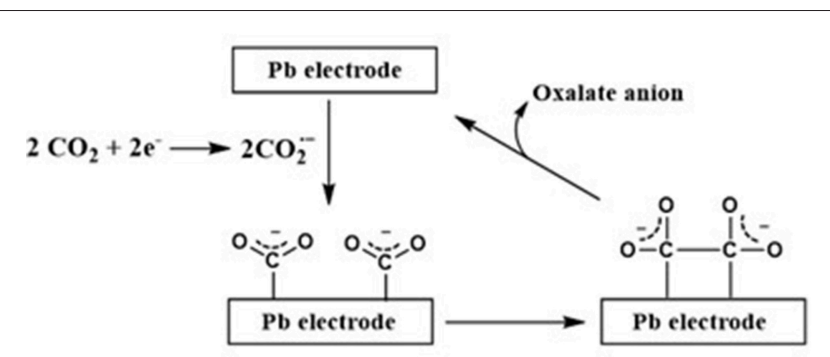

FIGURE 2 | The electrochemical reduction pathway for $\mathrm{CO}_{2}$ to $\mathrm{CO}$ at $\mathrm{Pd}$ electrode in acetonitrile. Adopted from Sun et al. (2014).

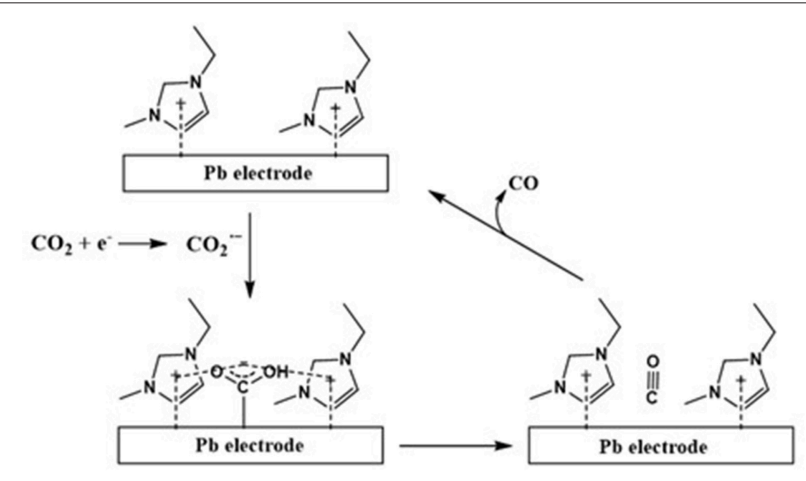

FIGURE 3 | The electrochemical reduction pathway for $\mathrm{CO}_{2}$ to $\mathrm{CO}$ at $\mathrm{Pd}$ electrode in [emim] $\left[\mathrm{Tf}_{2} \mathrm{~N}\right]$ /acetonitrile (CO formation). Adopted from Sun et al. (2014).

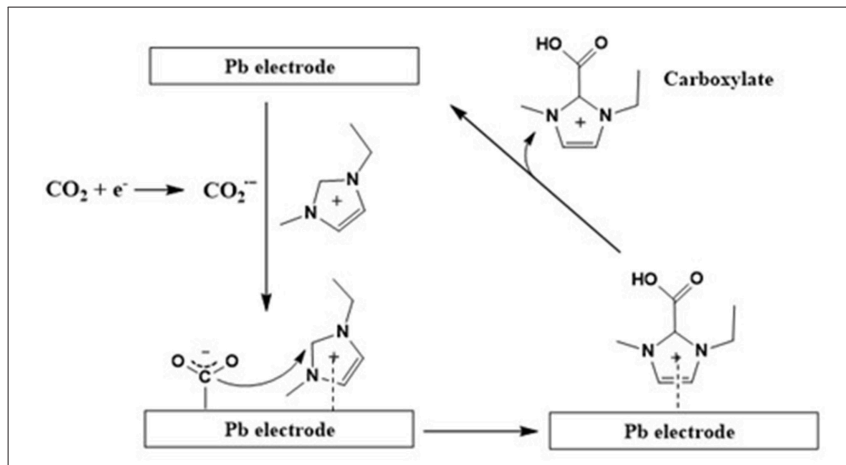

FIGURE 4 | The electrochemical reduction pathway for $\mathrm{CO}_{2}$ to $\mathrm{CO}$ at the $\mathrm{Pd}$ electrode in [emim] $\left[\mathrm{Tf}_{2} \mathrm{~N}\right]$ /acetonitrile (imidazolium carboxylate formation). Adopted from Sun et al. (2014).

for the formation of $\mathrm{CO}$ through electrochemical reduction of $\mathrm{CO}_{2}$. The author proposed that in the presence of a proton source such as water, the in-situ formed carboxylate species can decompose into $\mathrm{CO}$ and the active imidazolium cation can be recovered (Scheme 3). In this case, the author reported that the imidazolium cation served as a co-catalyst as it provides its own acidic proton in the $\mathrm{CO}$ formation process. However, the role of this co-catalysis is limited to the having a proton source in the reaction medium to recover the imidazolium cation in the catalytic cycle.

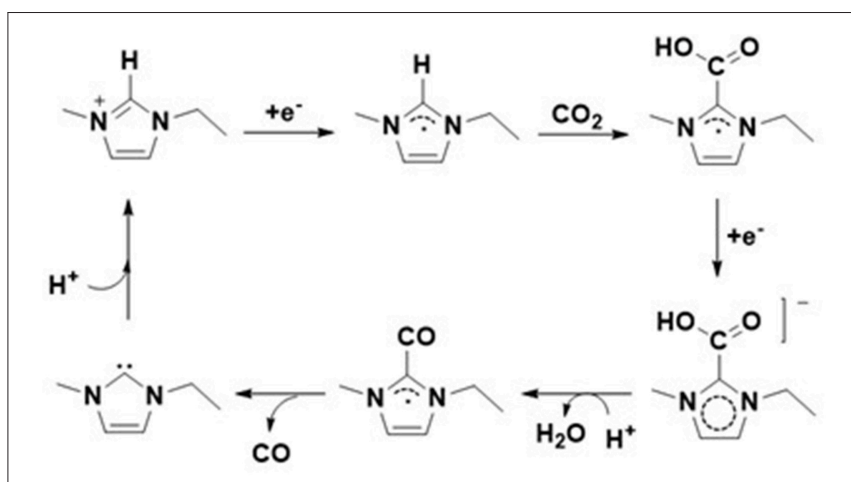

SCHEME 3 | Electrochemical reduction $\mathrm{CO}_{2}$ to $\mathrm{CO}$ through imidazolium carboxylate species. Adopted from Zhao et al. (2016).

Hence, even though the formation of $\mathrm{CO}$ can be explained based on different mechanistic approaches, these studies indicate that ILs are playing an important role upon electrochemical reduction of $\mathrm{CO}_{2}$ to $\mathrm{CO}$.

\section{Electrochemical Conversion of $\mathrm{CO}_{2}$ to Formic Acid/Formate}

The electrochemical conversion of $\mathrm{CO}_{2}$ to formic acid was also undertaken by several workers. Watkins and Bocarsly (2014) used 1-ethyl-3-methylimidazolium trifluoroacetate ([Emim][TFA $]$ ) along with various metals as co-catalysts in the electrochemical conversion of $\mathrm{CO}_{2}$ to $\mathrm{HCOOH}$ and found that iridium is an efficient catalyst. Hollingsworth et al. (2015) performed selective conversion of $\mathrm{CO}_{2}$ to formate and syngas by an anion assisted electrochemical process. The IL consisting of tetraalkylphosphonium cation and 1,2,4-triazolate anion $\left[\mathrm{P}_{66614}\right][1,2,4$ Triz $]$ absorbed equimolar amount of $\mathrm{CO}_{2}$ and assisted in the selective conversion of $\mathrm{CO}_{2}$ to formate under extremely low applied electrode potential $\left(-0.7 \mathrm{~V}\right.$ vs. $\left.\mathrm{Ag}^{+} / \mathrm{Ag}\right)$.

In a detailed study based on cyclic volumetric measurements for two different ILs, $\left[\mathrm{P}_{66614}\right][1,2,4$ Triz $]$ and $\left[\mathrm{P}_{66614}\right]\left[\mathrm{NTf}_{2}\right]$, the author observed that the $[1,2,4 \mathrm{Triz}]^{-}$anion comprising IL were found more efficient compared to their $\left[\mathrm{NTf}_{2}\right]^{-}$anion containing analogs upon electrochemical reaction of $\mathrm{CO}_{2}$ to $\mathrm{CO}$. In this case, in addition to physical interactions of the $\left[\mathrm{P}_{66614}\right]^{+}$cation with $\mathrm{CO}_{2}$ (i.e., formation of $\left[\mathrm{CO}_{2}\right]^{-}\left[\mathrm{P}_{66614}\right]^{+}$), the chemical interactions of the $[1,2,4 \mathrm{Triz}]^{-}$anion with $\mathrm{CO}_{2}$ allowed for low-energy electrochemical reaction of $\mathrm{CO}_{2}$ to $\mathrm{CO}$ (Scheme 4) compared to the case when the $\left[\mathrm{P}_{66614}\right]\left[\mathrm{NTf}_{2}\right]$ IL was employed.

Zhang et al. (2017) studied $\mathrm{CO}_{2}$ to formic acid conversion in the aqueous solution of 1-ethyl-3-methylimidazolium dicyanamide ([Emim $]\left[\mathrm{N}(\mathrm{CN})_{2}\right]$ ) using $\mathrm{Sn}$ powder electrode and noted that IL assisted in the electrochemical activation and conversion of $\mathrm{CO}_{2}$ to $\mathrm{HCOOH}$ but also increased the solubility of $\mathrm{CO}_{2}$ in the electrolyte system for maximum output. The $81.9 \%$ of Faradaic efficiency was achieved with $0.5 \mathrm{M}$ $[$ Emim $]\left[\mathrm{N}(\mathrm{CN})_{2}\right]$ in water, under the potential of $-1.2 \mathrm{~V}$ vs. reversible hydrogen electrode (RHE). Lu et al. (2017) first time introduced photo-electrochemical conversion of $\mathrm{CO}_{2}$ to 


$$
\text { [P6614][124Triz] }
$$

SCHEME 4 | Chemical interactions of $\left[\mathrm{P}_{66614}\right]\left[124\right.$ Triz] IL with $\mathrm{CO}_{2}$. Adopted from Wang et al. (2015).

$\mathrm{HCOOH}$ using functionalized IL such as 1-aminopropyl-3methylimidazolium bromide $\left(\left[\mathrm{NH}_{2} \mathrm{C}_{3} \mathrm{mim}\right] \mathrm{Br}\right)$ and the $94.1 \%$ faradaic efficiency was obtained for $\mathrm{HCOOH}$ conversion. The author claimed that the effective interaction of $\mathrm{CO}_{2}$ with the IL cation facilitated the conversion of $\mathrm{CO}_{2}$ to $\mathrm{HCOOH}$. Recently, Huan et al. (2017) observed a cost-effective electro-reduction of $\mathrm{CO}_{2}$ to $\mathrm{HCOOH}$ in [EMIM] $\left[\mathrm{BF}_{4}\right]$ using a copper-based electrocatalyst as cathode achieving high Faradaic efficiency $(87 \%$ for $8 \mathrm{~h})$. Compared to the electrochemical reduction of $\mathrm{CO}_{2}$ to $\mathrm{CO}$, the electrochemical transformation of $\mathrm{CO}_{2}$ to $\mathrm{HCOOH}$ or formate is still in its infancy in ILs and further addressing is required to understand the phenomena in detail.

\section{Electrochemical Conversion of $\mathrm{CO}_{2}$ to $\mathrm{CH}_{3} \mathrm{OH}$}

Similar to electrochemical conversion of $\mathrm{CO}_{2}$ to $\mathrm{CO}$ and $\mathrm{HCOOH}$, formation of methanol by electrochemical conversion of $\mathrm{CO}_{2}$ is another anticipated application and has been investigated extensively in ILs. Transformation of $\mathrm{CO}_{2}$ to methanol via electrochemical activation of $\mathrm{CO}_{2}$ has been performed recently by Han and coworkers (Sun et al., 2016). They used various bimetallic catalysts such as Mo-Bi, Mo-Ag, and $\mathrm{Mo}-\mathrm{Cu}$ in $[\mathrm{BmIm}]\left[\mathrm{BF}_{4}\right] /$ acetonitrile solution. The synergic effect of Mo and Bi metals as bimetallic catalyst upon electrochemical $\mathrm{CO}_{2}$-activation in $0.5 \mathrm{M}$ solution of IL in acetonitrile gave $71.2 \%$ Faradaic efficiency in methanol formation. In bimetal Mo-Bi catalyst, Mo facilitates conversion of $\mathrm{CO}_{2}$ to $\mathrm{CO}$ while $\mathrm{Bi}$ assists in the formation of $\mathrm{H}_{2}$ and adsorption of in-situ formed $\mathrm{CO}$ and, therefore, increases the possibility of hydrogenation of $\mathrm{CO}_{2}$ to $\mathrm{CH}_{3} \mathrm{OH}$.

Hence, RTILs play an important role in the electrochemical conversion of $\mathrm{CO}_{2}$ to various value-added and industrially important products such as $\mathrm{CO}, \mathrm{HCOOH}$, and $\mathrm{CH}_{3} \mathrm{OH}$. Though

\section{REFERENCES}

Aki, S., Mellein, B. R., Saurer, E. M., and Brennecke, J. F. (2004). High pressure phase behavior of carbon dioxide with imidazolium-based ionic liquids. J. Phys. Chem. B 108, 20355-20365. doi: 10.1021/jp04 $6895+$

Almantariotis, D., Gefflaut, T., Padua, A. A. H., Coxam, J. Y., and Costa Gomes, M. F. (2010). Effect of fluorination and size of the alkyl sidechain on the solubility of carbon dioxide in 1-alkyl-3-methylimidazolium bis(trifluoromethylsulfonyl)amide ionic liquids. J. Phys. Chem. B 114, 3608-3617. doi: 10.1021/jp912176n several hypotheses have been introduced to investigate the role of RTILs in the electrochemical reduction of $\mathrm{CO}_{2}$, none of them provide satisfactory information regarding the process. This could more be due to the complex structural and electronic nature of ILs at the IL-electrode interface than that of water. However, last but not least, ILs are proposed as a sustainable and green approach to activate and reduce the $\mathrm{CO}_{2}$ to essential chemical moieties with minimum energy consumption rather than the existing thermochemical approach.

\section{CONCLUSIONS AND OUTLOOK}

The remarkable properties of ILs over the conventional volatile solvents, such as non-volatility and structure-tunability, make them suitable for applications involving $\mathrm{CO}_{2}$ capture and fixation. The mini-review highlights the development in the $\mathrm{CO}_{2}$ uptake since the inception of ILs in this area and further development in the last decade. The effects of cations, anions, and functional groups on the physicochemical properties and their impact on $\mathrm{CO}_{2}$ uptake were reviewed, in both conventional and functionalized ILs. The forces involved in the $\mathrm{CO}_{2}$ capture and mechanism were discussed in various types of ILs. Despite the exciting response, the lack of inexpensive and diverse ILs poses a problem in applying them on large scale. Moreover, the impact of ILs on environment, corrosion, toxicity, and long-term stability need to be addressed.

\section{DATA AVAILABILITY}

All datasets generated for this study are included in the manuscript and the supplementary files.

\section{AUTHOR CONTRIBUTIONS}

All authors listed have made a substantial, direct and intellectual contribution to the work, and approved it for publication.

\section{ACKNOWLEDGMENTS}

We are thankful to the Wallenberg Wood Science Center (WWSC), Kempe Foundations, the Swedish Research Council, the Swedish Energy Agency, and the Bio4energy programme. This work is also part of the activities of the Johan Gadolin Process Chemistry Center at Åbo Akademi University. 
Bates, E. D., Mayton, R. D., Ntai, I., and Davis, J. H. (2002). $\mathrm{CO}_{2}$ capture by a taskspecific ionic liquid. J. Am. Chem. Soc. 124, 926-927. doi: 10.1021/ja017593d

Ben-Mansour, R., Habib, M. A., Bamidele, O. E., Basha, M., Qasem, N. A. A., Peedikakkal, A., et al. (2016). Carbon capture by physical adsorption: materials, experimental investigations and numerical modeling and simulations-A review. Appl. Energy 161, 225-255. doi: 10.1016/j.apenergy.2015.10.011

Cabaco, M. I., Besnard, M., Danten, Y., and Coutinho, J. A. P. (2011). Solubility of $\mathrm{CO}_{2}$ in 1-butyl-3-methyl-imidazolium-trifluoro acetate ionic liquid studied by raman spectroscopy and DFT investigations. J. Phys. Chem. B 115, 3538-3550. doi: $10.1021 /$ jp111453a

Cao, B. B., Du, J. Y., Liu, S. Y., Zhu, X., Sun, X. J., Sun, H. T., et al. (2016). Carbon dioxide capture by amino-functionalized ionic liquids: DFT based theoretical analysis substantiated by FT-IR investigation. RSC Adv. 6, 10462-10470. doi: 10.1039/C5RA23959A

Chaugule, A. A., Tamboli, A. H., and Kim, H. (2017). Ionic liquid as a catalyst for utilization of carbon dioxide to production of linear and cyclic carbonate. Fuel 200, 316-332. doi: 10.1016/j.fuel.2017.03.077

Chen, F.-F., Huang, K., Zhou, Y., Tian, Z.-Q., Zhu, X., Tao, D.-J., et al. (2016). Multi-molar absorption of $\mathrm{CO}_{2}$ by the activation of carboxylate groups in amino acid ionic liquids. Angew. Chem. Int. Ed. 55, 7166-7170. doi: 10.1002/anie.201602919

Chen, Y., Li, C. W., and Kanan, M. W. (2012). Aqueous $\mathrm{CO}_{2}$ reduction at very low overpotential on oxide-derived Au nanoparticles. J. Am. Chem. Soc. 134, 19969-19972. doi: 10.1021/ja309317u

Chueh, W. C., Falter, C., Abbott, M., Scipio, D., Furler, P., Haile, S. M., et al. (2010). High-flux solar-driven thermochemical dissociation of $\mathrm{CO}_{2}$ and $\mathrm{H}_{2} \mathrm{O}$ using nonstoichiometric ceria. Science 330, 1797-1801. doi: 10.1126/science.1197834

Costentin, C., Drouet, S., Robert, M., and Saveant, J.-M. (2012). A local proton source enhances $\mathrm{CO}_{2}$ electroreduction to $\mathrm{CO}$ by a molecular Fe catalyst. Science 338, 90-94. doi: 10.1126/science. 1224581

Feng, J., Zeng, S., Feng, J., Dong, H., and Zhang, X. (2018a). $\mathrm{CO}_{2}$ electroreduction in ionic liquids: a review. Chin. J. Chem. 36, 961-970. doi: $10.1002 /$ cjoc.201800252

Feng, J., Zeng, S., Liu, H., Feng, J., Gao, H., Bai, L., et al. (2018b). Insights into carbon dioxide electroreduction in ionic liquids: carbon dioxide activation and selectivity tailored by ionic microhabitat. ChemSusChem 11, 3191-3197. doi: 10.1002/cssc.201801373

Friedlingstein, P., Solomon, S., Plattner, G.-K., Knutti, R., Ciais, P., and Raupach, M. R. (2011). Long-term climate implications of twenty-first century options for carbon dioxide emission mitigation. Nat. Clim. Change 1, 457-461. doi: $10.1038 /$ nclimate 1302

George, G., Bhoria, N., AlHallaq, S., Abdala, A., and Mittal, V. (2016). Polymer membranes for acid gas removal from natural gas. Sep. Purif. Technol. 158, 333-356. doi: 10.1016/j.seppur.2015.12.033

Goodrich, B. F., de la Fuente, J. C., Gurkan, B. E., Zadigian, D. J., Price, E. A., Huang, Y., et al. (2011). Experimental measurements of amine-functionalized anion-tethered ionic liquids with carbon dioxide. Ind. Eng. Chem. Res. 50, 111-118. doi: 10.1021/ie101688a

Gurkan, B. E., de la Fuente, J. C., Mindrup, E. M., Ficke, L. E., Goodrich, B. F., Price, E. A., et al. (2010b). Equimolar $\mathrm{CO}_{2}$ absorption by anion-functionalized ionic liquids. J. Am. Chem. Soc. 132, 2116-2117. doi: 10.1021/ja90 $9305 \mathrm{t}$

Gurkan, B. E., Goodrich, B. F., Mindrup, E. M., Ficke, L. E., Massel, M., Seo, S., et al. (2010a). Molecular design of high capacity, low viscosity, chemically tunable ionic liquids for $\mathrm{CO}_{2}$ capture. J. Phys. Chem. Lett. 1, 3494-3499. doi: $10.1021 / \mathrm{jz} 101533 \mathrm{k}$

Hollingsworth, N., Taylor, S. F. R., Galante, M. T., Jacquemin, J., Longo, C., Holt, K. B., et al. (2015). Reduction of carbon dioxide to formate at low overpotential using a superbase ionic liquid. Angew. Chem. Int. Ed. 54, 14164-14168. doi: 10.1002/anie.201507629

Hu, J., Ma, J., Liu, H., Qian, Q., Xie, C., and Han, B. (2018). Dual-ionic liquid system: an efficient catalyst for chemical fixation of $\mathrm{CO}_{2}$ to cyclic carbonates under mild conditions. Green Chem. 20, 2990-2994. doi: 10.1039/C8GC0 $1129 \mathrm{~J}$

Huan, T. N., Simon, P., Rousse, G., Genois, I., Artero, V., and Fontecave, M. M. (2017). Porous dendritic copper: an electrocatalyst for highly selective $\mathrm{CO}_{2}$ reduction to formate in water/ionic liquid electrolyte. Chem. Sci. 8, 742-747. doi: 10.1039/C6SC03194C
Huang, K., Zhang, X. M., Xu, Y., Wu, Y. T., Hu, X. B., and Xu, Y. (2014). Protic ionic liquids for the selective absorption of $\mathrm{H}_{2} \mathrm{~S}$ from $\mathrm{CO}_{2}$ : thermodynamic analysis. AIChE J. 60, 4232-4240. doi: 10.1002/aic.14634

Kasahara, S., Kamio, E., Shaikh, A. R., Matsuki, T.;, and Matsuyama, H. (2016). Effect of the amino-group densities of functionalized ionic liquids on the facilitated transport properties for $\mathrm{CO}_{2}$ separation. J. Membr. Sci. 503, 148-157. doi: 10.1016/j.memsci.2016.01.007

Kazarian, S. G., Briscoe, B. J., and Welton, T. (2000). Combining ionic liquids and supercritical fluids: in situ ATR-IR study of $\mathrm{CO}_{2}$ dissolved in two ionic liquids at high pressures. Chem. Commun. 20, 2047-2048. doi: 10.1039/B005514J

Lee, T. B., Oh, S., Gohndrone, T. R., Morales-Collazo, O., Seo, S., Brennecke, J. F., et al. (2016). $\mathrm{CO}_{2}$ chemistry of phenolate-based ionic liquids. J. Phys. Chem. B 120, 1509-1517. doi: 10.1021/acs.jpcb.5b06934

Lei, Z. G., Dai, C. N., and Chen, B. H. (2014). Gas solubility in ionic liquids. Chem. Rev. 114, 1289-1326. doi: 10.1021/cr300497a

Li, Z., Wang, Q., Liu, D., Yang, B., Zhang, X., and Lei, L. (2013). Ionic liquidmediated electrochemical $\mathrm{CO}_{2}$ reduction in a microbial electrolysis cell. Electrochem. Commun. 35, 91-93. doi: 10.1016/j.elecom.2013.08.002

Lim, H.-K., and Kim, H. (2017). The mechanism of room-temperature ionicliquid-based electrochemical $\mathrm{CO}_{2}$ reduction: a review. Molecules 22, 536-541. doi: 10.3390/molecules 22040536

Liu, X. M., Zhou, G. H., Zhang, S. J., and Yao, X. Q. (2009). Molecular dynamics simulation of dual amino-functionalized imidazolium-based ionic liquids. Fluid Phase Equilib. 284, 44-49. doi: 10.1016/j.fluid.2009.06.004

Liu, X. Y., Huang, Y., Zhao, Y. S., Gani, R., Zhang, X. P., and Zhang, S. J. (2016). Ionic liquid design and process simulation for decarbonization of shale gas. Ind. Eng. Chem. Res. 55, 5931-5944. doi: 10.1021/acs.iecr. $6 \mathrm{~b} 00029$

Lu, W., Jia, B., Cui, B., Zhang, Y., Yao, K., Zhao, Y., et al. (2017). Efficient photoelectrochemical reduction of carbon dioxide to formic acid: a functionalized ionic liquid as an absorbent and electrolyte. Angew. Chem. Int. Ed. 56, 11851-11854. doi: 10.1002/anie.201703977

Luo, X. Y., Guo, Y., Ding, F., Zhao, H. Q., Cui, G. K., Li, H. R., et al. (2014). Significant improvements in $\mathrm{CO}_{2}$ capture by pyridine-containing anionfunctionalized ionic liquids through multiple-site cooperative interactions. Angew. Chem. Int. Ed. 53, 7053-7057. doi: 10.1002/anie.201400957

Martínez-Ferraté, O., Chacón, G., Bernardi, F., Grehl, T., Brüner, P., and Dupont, J. (2018). Cycloaddition of carbon dioxide to epoxides catalysed by supported ionic liquids. Catal. Sci. Technol. 8, 3081-3089. doi: 10.1039/C8CY00749G

Muldoon, M. J., Aki, S. N. V. K., Anderson, J. L., Dixon, J. K., and Brennecke, J. F. (2007). Improving carbon dioxide solubility in ionic liquids. J. Phys. Chem. B 111, 9001-9009. doi: 10.1021/jp071897q

Mumford, K. A., Wu, Y., Smith, K. H., and Stevens, G. W. (2015). Review of solvent based carbon-dioxide capture technologies. Front. Chem. Sci. Eng. 9, 125-141. doi: 10.1007/s11705-015-1514-6

Niedermaier, I., Bahlmann, M., Papp, C., Kolbeck, C., Wei, W., Calderon, S. K., et al. (2014). Carbon dioxide capture by an amine functionalized ionic liquid: fundamental differences of surface and bulk behavior. J. Am. Chem. Soc. 136, 436-441. doi: 10.1021/ja410745a

Oh, Y., and $\mathrm{Hu}, \mathrm{X}$. (2013). Organic molecules as mediators and catalysts for photocatalytic and electrocatalytic $\mathrm{CO}_{2}$ reduction. Chem. Soc. Rev. 42, 2253-2261. doi: 10.1039/C2CS35276A

Palomar, J., Gonzalez-Miquel, M., Polo, A., and Rodriguez, F. (2011). Understanding the physical absorption of $\mathrm{CO}_{2}$ in ionic liquids using the COSMO-RS method. Ind. Eng. Chem. Res. 50, 3452-3463. doi: $10.1021 /$ ie $101572 \mathrm{~m}$

Peng, J., and Deng, Y. (2001). Cycloaddition of carbon dioxide to propylene oxide catalyzed by ionic liquids. New J. Chem. 25, 639-641. doi: 10.1039/B00 $8923 \mathrm{~K}$

Rebecca, S. F., McCrellis, T. C., McStay, C., Jacquemin, J., Hardacre, C., Mercy, M., et al. (2015). $\mathrm{CO}_{2}$ capture in wet and dry superbase ionic liquids. J Solution Chem. 44, 511-527. doi: 10.1007/s10953-015-0319-z

Rosen, B. A., Salehi-Khojin, A., Thorson, M. R., Zhu, W., Whipple, D. T., Kenis, P. J. A., et al. (2011). Ionic liquid-mediated selective conversion of $\mathrm{CO}_{2}$ to $\mathrm{CO}$ at low overpotentials. Science 334, 642-643. doi: 10.1126/science

Sanz-Perez, E. S., Murdock, C. R., Didas, S. A., and Jones, C. W. (2016). Direct capture of $\mathrm{CO}_{2}$ from ambient air. Chem. Rev. 116, 11840-11876. doi: $10.1021 /$ acs.chemrev.6b00173 
Shao, R., and Stangeland, A. (2009). Amines Used in $\mathrm{CO}_{2}$ Capture-Health and Environmental Impacts. Oslo: The Bellona Foundation.

Spinner, N. S., Vega, J. A., and Mustain, W. E. (2012). Recent progress in the electrochemical conversion and utilization of $\mathrm{CO}_{2}$. Catal. Sci. Technol. 2, 19-28. doi: 10.1039/C1CY00314C

Steinruck, H.-P., and Wasserscheid, P. (2015). Ionic liquids in catalysis. Catal. Lett. 145, 380-397. doi: 10.1007/s10562-014-1435-x

Sun, L., Ramesha, G. K., Kamat, P. V., and Brennecke, J. F. (2014). Switching the reaction course of electrochemical $\mathrm{CO}_{2}$ reduction with ionic liquids. Langmuir 30, 6302-6308. doi: 10.1021/la5009076

Sun, X., Zhu, Q., Kang, X., Liu, H., Qian, Q., Zhang, Z., et al. (2016). Molybdenumbismuth bimetallic chalcogenide nanosheets for highly efficient electrocatalytic reduction of carbon dioxide to methanol. Angew. Chem. Int. Ed. 55, 6771-6775. doi: 10.1002/anie.201603034

Thitakamol, B., Veawab, A., and Aroonwilas, A. (2007). Environmental impacts of absorption-based $\mathrm{CO}_{2}$ capture unit for post-combustion treatment of flue gas from coal-fired power plant. Int. J. Greenhousen Gas Control 1, 318-342. doi: 10.1016/S1750-5836(07)00042-4

Vafaeezadeh, M., Aboudi, J., and Hashemi, M. M. (2015). A novel phenolic ionic liquid for 1.5 molar $\mathrm{CO}_{2}$ capture: combined experimental and DFT studies. RSC Adv. 5, 58005-58009. doi: 10.1039/C5RA09845A

Wang, C. M., Luo, H. M., Jiang, D. E., Li, H. R., and Dai, S. (2010). Carbon dioxide capture by superbase-derived protic ionic liquids. Angew. Chem. Int. Ed. 49, 5978-5981. doi: 10.1002/anie.201002641

Wang, C. M., Luo, H. M., Li, H. R., Zhu, X., Yu, B., and Dai, S. (2012). Tuning the physicochemical properties of diverse phenolic ionic liquids for equimolar $\mathrm{CO}_{2}$ capture by the substituent on the anion. Chem. Eur. J. 18, 2153-2160. doi: 10.1002/chem.201103092

Wang, C. M., Luo, X. Y., Luo, H. M., Jiang, D. E., Li, H. R., and Dai, S. (2011). Tuning the basicity of ionic liquids for equimolar $\mathrm{CO}_{2}$ capture. Angew. Chem. Int. Ed. 50, 4918-4922. doi: 10.1002/anie.201008151

Wang, Y., Hatakeyama, M., Ogata, K., Wakabayashi, M., Jinb, F., and Nakamura, S. (2015). Activation of $\mathrm{CO}_{2}$ by ionic liquid EMIM-BF $\mathrm{B}_{4}$ in the electrochemical system: a theoretical study. Phys. Chem. Chem. Phys. 17, 23521-23531. doi: 10.1039/C5CP02008E

Watkins, J. D., and Bocarsly, A. B. (2014). Direct reduction of carbon dioxide to formate in high-gas-capacity ionic liquids at post-transition-metal electrodes. ChemSusChem 7, 284-290. doi: 10.1002/cssc.201300659

Xiaoding, X., and Moulijn, J. A. (1996). Mitigation of $\mathrm{CO}_{2}$ by chemical conversion: plausible chemical reactions and promising products. Energy Fuels 10, 305-325. doi: 10.1021/ef9501511

Xu, B.-H., Wang, J.-Q., Sun, J., Huang, Y., Zhang, J.-P., Zhang, X.-P., et al. (2015). Fixation of $\mathrm{CO}_{2}$ into cyclic carbonates catalyzed by ionic liquids: a multi-scale approach. Green Chem.17, 108-122. doi: 10.1039/C4GC01754D

Zeng, S., Zhang, X., Bai, L., Zhang, X., Wang, H., Wang, J., et al. (2017). Ionicliquid-based $\mathrm{CO}_{2}$ capture systems: structure, interaction and process. Chem. Rev. 117, 9625-9673. doi: 10.1021/acs.chemrev.7b00072
Zeng, S. J., Wang, J., Bai, L., Wang, B. Q., Gao, H. S., Shang, D. W., et al. (2015). Highly selective capture of $\mathrm{CO}_{2}$ by ether-functionalized pyridinium ionic liquids with low viscosity. Energy Fuels 29, 6039-6048. doi: 10.1021/acs.energyfuels.5b01274

Zhang, X., Zhao, Y., Hu, S., Gliege, M. E., Liu, Y., Liu, R., et al. (2017). Electrochemical reduction of carbon dioxide to formic acid in ionic liquid $[\mathrm{EmIm}]\left[\mathrm{N}(\mathrm{CN})_{2}\right] /$ water system. Electrochim. Acta 247, 281-287. doi: 10.1016/j.electacta.2017.06.112

Zhang, X. C., Huo, F., Liu, Z. P., Wang, W. C., Shi, W., and Maginn, E. J. (2009). Absorption of $\mathrm{CO}_{2}$ in the ionic liquid 1-n-hexyl-3- methylimidazolium tris(pentafluoroethyl)trifluorophosphate $([\mathrm{hmim}][\mathrm{FEP}])$ a molecular view by computer simulations. J. Phys. Chem. B 113, 7591-7598. doi: 10.1021/jp900403q

Zhang, Y. Q., Zhang, S. J., Lu, X. M., Zhou, Q., Fan, W., and Zhang, X. P. (2009). Dual amino-functionalised phosphonium ionic liquids for $\mathrm{CO}_{2}$ capture. Chem. Eur. J. 15, 3003-3011. doi: 10.1002/chem.200801184

Zhao, S., Tian, X. Z., Liu, J. N., Ren, Y. L., and Wang, J. J. (2015). A theoretical investigation on the adsorption of $\mathrm{CO}_{2}, \mathrm{~N}_{2}, \mathrm{O}_{2}$ and $\mathrm{H}_{2}$ in 1-buty3-methylimidazolium heptafluorobutyrate ionic liquid. Comput. Theor. Chem. 1052, 12-16. doi: 10.1021/jp205830d

Zhao, S.-F., Horne, M., Bond, A. M., and Zhang, J. (2016). Is the imidazolium cation a unique promoter for electrocatalytic reduction of carbon dioxide? J. Phys. Chem. C 120, 23989-24001. doi: 10.1021/acs.jpcc.6b08182

Zhao, T., Hu, X., Wu, D., Li, R., Yang, G., and Wu, Y. (2017). Direct synthesis of dimethyl carbonate from carbon dioxide and methanol at room temperature using imidazolium hydrogen carbonate ionic liquid as a recyclable catalyst and dehydrant. ChemSusChem 10, 2046-2052. doi: 10.1002/cssc.201700128

Zhao, Y. S., Zhang, X. P., Zhen, Y. P., Dong, H. F., Zhao, G. Y., Zeng, S. J., et al. (2011). Novel alcamines ionic liquids based solvents: preparation, characterization and applications in carbon dioxide capture. Int. J. Greenhouse Gas Control 5, 367-373. doi: 10.1016/j.ijggc.2010.09.010

Zhu, X., Lu, Y. X., Peng, C. J., Hu, J., Liu, H. L., and Hu, Y. (2011). Halogen bonding interactions between brominated ion pairs and $\mathrm{CO}_{2}$ molecules: implications for design of new and efficient ionic liquids for $\mathrm{CO}_{2}$ absorption. J. Phys. Chem. B 115, 3949-3958. doi: 10.1021/jp111194k

Conflict of Interest Statement: The authors declare that the research was conducted in the absence of any commercial or financial relationships that could be construed as a potential conflict of interest.

Copyright (C) 2019 Shukla, Khokarale, Bui and Mikkola. This is an open-access article distributed under the terms of the Creative Commons Attribution License (CC BY). The use, distribution or reproduction in other forums is permitted, provided the original author(s) and the copyright owner(s) are credited and that the original publication in this journal is cited, in accordance with accepted academic practice. No use, distribution or reproduction is permitted which does not comply with these terms. 